\title{
$P$ - AND S-PHASE DATA FROM LOCAL EARTHQUAKES IN SOUTHERN CALIFORNIA FOR 1966 TO 1975
}

\section{By JAMES H. WHITCOMB}

The purpose of this note is to describe a card-image computer tape now available with earthquake epicenter and $P$ - and $S$-phase data for local earthquakes in Southern California during the 10-year period of 1966 through 1975. The tape is readable on an IBM 370/158 computer using standard FORTRAN READ statements. The tape is currently being used for several research projects including event relocation, velocity, $P$-delay, and magnitude studies. This research resource is being made available to all scientific investigators.

The Seismological Laboratory was founded by the Carnegie Institution of Washington in 1927 and management was transferred to the California Institute of Technology (Caltech) in 1936. Although some seismographic stations of the Caltech network were established as early as 1926 , routine and systematic epicentral determinations started only in 1932, with 7 stations reporting. By 1966, the beginning of the data tape, the network had expanded to 19 stations. By 1972, 39 stations were being read for earthquake phases. During the period from 1972 through 1975, a cooperative program was established with the U.S. Geological Survey and a major expansion of the Southern California network increased the total number of stations to 103 as shown in Figure 1. Currently, the number of stations is approaching 150. This exponentially expanding data base has threatened to saturate even routine analysis of local earthquakes and led to the development of more automated methods of recording and analysis. These new methods include the Caltech Earthquake Detection and Recording (CEDAR) system, which has been in operation since January 1, 1977 and will be reported elsewhere (Johnson, in preparation). Automated earthquake analysis systems need a means to extrapolate their results to past data which, until the generation of this magnetic tape, have been inaccessible for computer processing. The magnetic tape contains approximately 150,000 card images representing more than 200,000 individual earthquake readings that were punched from hand-written data cards. Of the 200,000 readings, more than one-half are from the last 2 years (1974 to 1975) of the 10-year interval, representing an increase in both the number of stations and the sensitivity of detection/location thresholds.

The data tape is formated chronologically by event such that each event begins with a hypocenter description card followed by $P$ - and $S$-phase cards for that event. Some phase data follows blank hypocenter cards indicating that the phase data was deemed insufficient to attempt a hypocentral location. One year of data is limited to one tape file, and there are as many records within each file as necessary; records are limited to 1000 cards or less.

Although every attempt has been made to correct errors during punching of cards and during research on selected parts of the data set, errors certainly remain. While some errors are obvious, and can be corrected within analysis programs, a systematic search for more subtle reading and punching errors for the entire 10-year span of the data is beyond our current resources. It is felt that, instead of waiting for systematic checking of data on the tape, interested scientists outside our institute would prefer to take advantage of this research data source in its present form. It is 
requested that errors detected by others during their use of this data be brought to the author's attention in order that later versions of the data tape can be corrected. Data for smaller events from special studies may yet be missing, mainly in the year 1975 , and should be included in later versions.

During the 1966 to 1975 10-year data span, hypocenters have been computed with different location programs and different assumptions as to velocity models and station delays. Hopefully, these variables have been modified with time toward

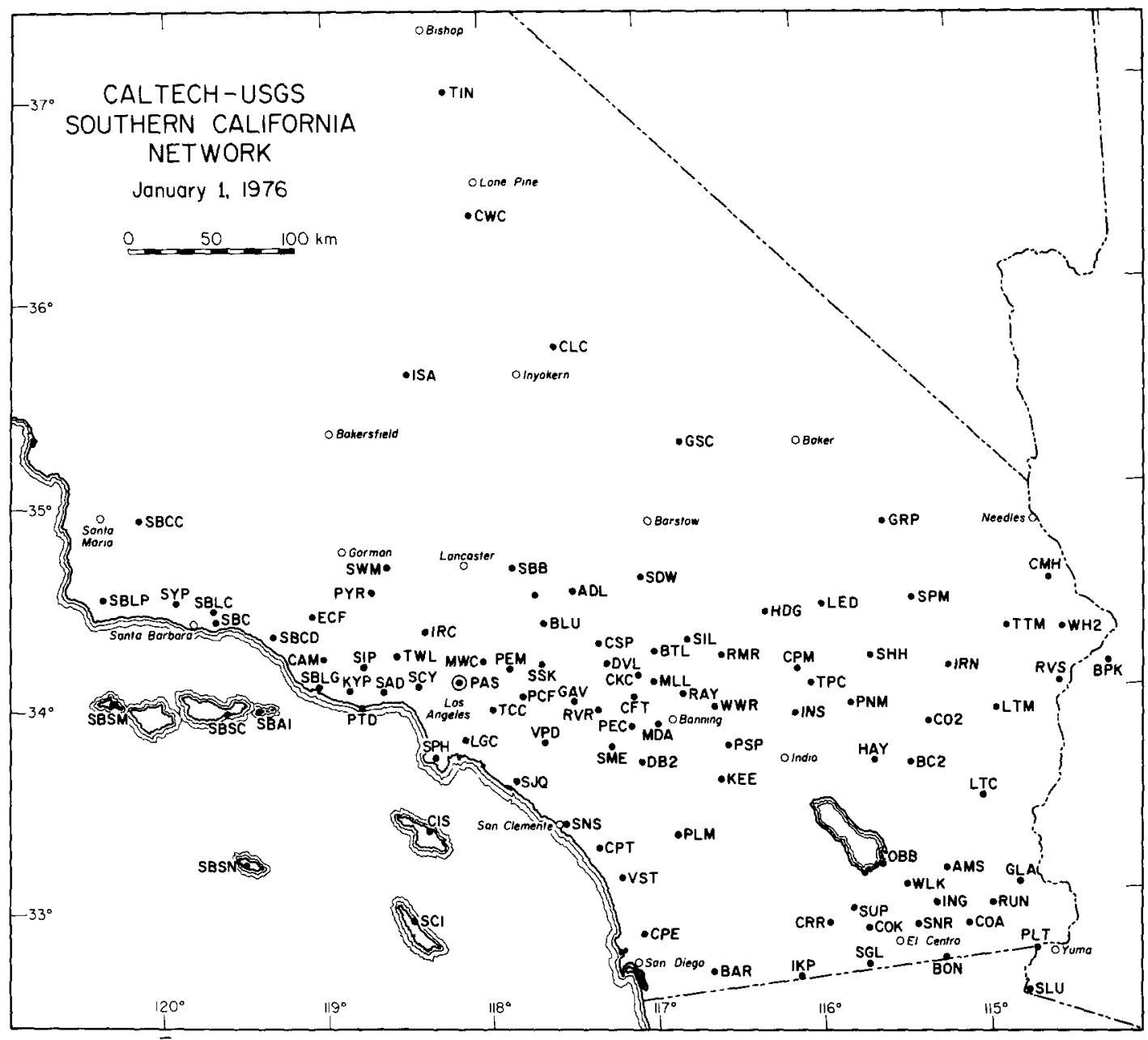

FIG. 1. Stations of the Caltech-USGS Southern California Seismographic Network that were in operation on January 1, 1976 at the end of the 10-year period of the data tape for 1966 to 1975.

improved hypocentral locations. But those studies depending on the uniformity and relative precision of hypocenter calculations during the 10-year span will probably require recomputation with uniform location parameters. Indeed, one of the major incentives for making the phase data available to computation is to remove the dependence of such studies on the particular method and assumptions of hypocentral computation which change over a long time span.

In order to obtain a copy of the tape, investigators should send the author a blank tape with a written request for the data. A fee will be charged for tape copying and 
handling. Publications dealing with seismicity of Southern California during this time period are Hileman et al. (1973) and Friedman et al. (1976).

\section{ACKNOWLEDGMENTS}

I thank Marla Turner who did most of the long and difficult task of data keypunching and organization and the many other workers who read phases and punched cards for this data set. I thank the U.S. Geological Survey personnel who kindly provided copies of data cards for their stations under the Caltech-USGS cooperation program in Southern California. The efforts of the technical personnel who have dependably maintained the stations and equipment that are the source of this data are greatly appreciated. This work was supported by NASA/JPL Grant 49-681-02081-0-3260 and by the Nuclear Regulatory Commission Grant AT(49-24)-0195.

\section{REFERENCES}

Hileman, J. A., C. R. Allen, and J. M. Nordquist (1973). Seismicity of the Southern California region, 1 January 1932 to 31 December 1972, Seismological Laboratory, California Institute of Technology, Pasadena, 487 pp.

Friedman, M. E., J. H. Whitcomb, C. R. Allen, and J. A. Hileman (1976). Seismicity of the Southern California Region 1 January 1972 to 31 December 1974, Seismological Laboratory, California Institute of Technology, Pasadena, $92 \mathrm{pp}$.

SFISMOLOGICAL LABORATORY

California Institute of TEChNOLOGY

Pasadena, California 91125

Division of Geological and Planetary Siences

California Institute of Technology

Contribution No. 2982

Manuscript received October 27, 1977 